\title{
Atuação de Psicólogas(os) na Escola: Enfrentando Desafios na Proposição de Práticas Críticas
}

\author{
Paula Costa de Andrada ${ }^{1}$ \\ ${ }^{1}$ Centro Universitário UNIFAAT, SP, Brasil. \\ Ana Paula Petroni² \\ ${ }^{2}$ Pontifícia Universidade Católica de Campinas, \\ SP, Brasil.
}

\author{
Lilian Aparecida Cruz Dugnani ${ }^{2}$ \\ ${ }^{2}$ Pontifícia Universidade Católica de Campinas, \\ SP, Brasil. \\ Vera Lucia Trevisan de Souza ${ }^{2}$ \\ ${ }^{2}$ Pontificia Universidade Católica de Campinas, \\ SP, Brasil.
}

Resumo: Este artigo visa contribuir para a discussão e constituição de formas de atuação de psicólogas(os) na escola, que se oponham aos modelos clínicos, medicalizantes e biologizantes por vezes ainda hegemônicos. De natureza teórico-reflexiva, assume os pressupostos teóricometodológicos da Psicologia Histórico-Cultural, sobretudo os formulados por Vigotski, que vêm fundamentando investigações e atuações na área da Psicologia Escolar e Educacional Crítica, visando à superação dos desafios da Educação Básica, e que tem se objetivado por meio de práticas psicológicas dialógicas, reflexivas e integradoras do desenvolvimento humano; que consideram o contexto e as condições concretas de vida dos sujeitos compreendendo que estas ações só podem ser operacionalizadas no e com o coletivo e que a parceria com os educadores é mola propulsora dessa forma de atuação. Como formadoras e pesquisadoras na área da Psicologia Escolar, reafirmamos nosso engajamento na luta pela defesa do lugar de profissionais da Psicologia na equipe técnica da escola, e no combate a formas de atuação que tomam por base a queixa escolar centrada no aluno ou suas famílias, de modo a construir uma prática que contribua efetivamente para o desenvolvimento de todos os envolvidos no longo e complexo processo de educação escolarizada.

Palavras-chave: Psicologia Histórico-Cultural, Psicologia Escolar e Educacional, Psicologia da Arte e Processos Grupais, Práticas Psicológicas. 


\title{
Psychologists' Performance at School: Facing Challenges in Proposing Critical Practices
}

\begin{abstract}
This article aims to contribute to the discussion and constitution of ways of acting of psychologists in the school, in opposition to the clinical, medicalizing and biologizing models, sometimes still hegemonic. Of theoretical and methodological nature, this study assumes the theoretical-methodological assumptions of Historical-Cultural Psychology, especially those formulated by Vygotsky, which have been the basis for investigations and actions in the area of Critical School Psychology, aiming at overcoming the challenges of Basic Education, and which has been objectified through dialogic, reflective and integrative human development psychological practices that consider the context and concrete life conditions of the subjects, understanding that these actions can only be operationalized in and with the collective, and that the partnership with educators is the driving force of this way of acting. As university professors and researchers of the school Psychology area, we reaffirm our commitment to defend the place of Psychology professionals in the technical team of the school, and in the fight against forms of action that are based on the school complaint centered on students or on their families, in order to build a practice that effectively contributes to the development of all those involved in the long and complex process of schooling.
\end{abstract}

Keywords: Historic-Cultural Psychology, Educational and School Psychology, Psychology of Art, Group Processes, Psychological Practices.

\section{Actuación de Psicólogas(os) en la Escuela: Enfrentando Desafíos para Proponer Prácticas Críticas}

Resumen: Este artículo pretende contribuir a la discusión y constitución de formas de actuación de psicólogas(os) en la escuela, que se oponen a los modelos clínicos de medicalización y patologización de la educación, a veces aún hegemónicos. De naturaleza teórico-reflexiva, asume los supuestos teórico-metodológicos de la Psicología Histórico-Cultural, especialmente aquellos formulados por Vigotski, que han sido la base de investigaciones y actuaciones en el área de la Psicología Escolar Crítica, visando la superación de los desafíos de la Educación Básica, y que se ha objetivado por medio de prácticas psicológicas dialógicas, reflexivas e integradoras del desarrollo humano; que consideran el contexto y las condiciones concretas de vida de los sujetos comprendiendo que estas acciones sólo pueden ser operacionalizadas en el y con el colectivo y que la asociación con los educadores es la fuerza motriz de esta forma de actuar. Como formadoras e investigadoras en el área de la Psicología Escolar, reafirmamos nuestro compromiso en la lucha por la defensa del lugar de los profesionales de la Psicología en el equipo técnico de la escuela, y en el combate a formas de actuación que toman por base la queja escolar centrada en el alumno o sus familias, de modo a construir una práctica psicológica que contribuya efectivamente al desarrollo de todos los involucrados en el largo y complejo proceso de educación escolarizada.

Palabras clave: Psicología Histórico-cultural, Psicología Escolar y Educacional, Psicología del Arte, Procesos Grupales y Prácticas Psicológicas. 


\section{Introdução}

O que fazem as(os) profissionais de Psicologia na escola? Que contribuições têm a oferecer para a superação das demandas desse contexto? Responder a essas questões nos coloca frente a dois desafios: compreender quais as ações de psicólogas e psicólogos podem contribuir para a efetivação de um processo de ensino e de aprendizagem promotor de desenvolvimento e oferecer reflexões que fundamentam teoricamente a constituição dessas práticas psicológicas que temos denominado de críticas.

Nossas ações, em pesquisa e intervenção, se voltam ao coletivo da escola e assumem a dialogia como perspectiva e mediação. As expressões por meio da fala e as reflexões que emergem do movimento da fala-escuta têm favorecido a ressignificação do cotidiano por educadores e educandos, e contribuído para a ampliação da consciência, entendida como novos modos de perceber, compreender e pensar a realidade em relação a si próprio, ao outro e às condições materiais (Andrada \& Souza, 2015; Barbosa \& Souza, 2015; Souza, Dugnani, Petroni \& Andrada, 2015; Dugnani \& Souza, 2016; Souza, 2016a).

Como estratégia favorecedora da constituição da relação entre os sujeitos, logo, da construção do coletivo, os pressupostos da Psicologia da Arte de Vygotsky (1925/2001), entendidos como a potência da arte para afetar o outro, têm se mostrado efetivos na promoção do diálogo e da reflexão em um meio em que, por vezes, são raros os momentos para a expressão da fala, dos sentimentos, ou mesmo para o exercício da reflexão. No cerne do fundamento da utilização de expressões artísticas como estratégias de ações voltadas à promoção do desenvolvimento está nossa compreensão de que a apreciação de formas de arte produz estranhamento da realidade, colocando em movimento o que aparenta estar imóvel, favorecendo novas significações. De nossa perspectiva, o uso da arte como mediadora dos diálogos na escola, rompe com os rótulos e com os movimentos de culpabilização do outro que caracteriza a queixa escolar, aumentando a potência de ação, a um só tempo, de todos e de cada um (Souza, Dugnani \& Reis, 2018).

As publicações abordando a Psicologia Escolar e Educacional demonstram que a área vem se firmando e sendo legitimada por sua relevância no campo psicossocial. O cenário de desigualdade social e educacional da escola brasileira, por si só, justifica o investimento em estudos de novas formas de intervenções, não apenas nas escolas, mas em todo o contexto educativo (Guzzo, Mezzalira, Moreira, Tizzei, \& Silva, 2010).

É importante compreender a própria nomenclatura desta área, que congrega dois campos de produção de conhecimento e atuação que se imbricam de modo indissociável - Psicologia Educacional/Escolar. A Psicologia Educacional se constitui como a área de conhecimento da Psicologia que se dedica à construção de um:

córpus sistemático e organizado de saberes produzidos de acordo com procedimentos definidos, referentes a determinados fenômenos ou conjunto de fenômenos constituintes da realidade, fundamentado em concepções ontológicas, epistemológicas, metodológicas e éticas determinadas (Antunes, 2008, p. 470).

Já a Psicologia Escolar se volta à produção de conhecimentos e práticas que devem subsidiar a atuação destas(es) profissionais, e tem como objeto a escola e as relações que nela se desenvolvem, com foco nos sujeitos que se empreendem em práticas educativas, sejam alunos, professores, gestores, famílias e comunidade. Importa destacar que tanto a Psicologia Escolar quanto a Educacional são marcadas pela diversidade de abordagens e teorias que constituem a Psicologia enquanto ciência (Antunes, 2008). No entanto, os saberes produzidos constituirão as bases para a construção de atuações mais criativas na escola, do mesmo modo que a prática profissional será fonte inesgotável de questões a serem investigadas cientificamente neste âmbito.

É nesse sentido que afirmamos que as perspectivas para a inserção da(o) psicóloga(o) como profissional da educação em âmbito nacional, que não acontece ainda hoje, principalmente pela falta de uma política pública que garanta à população mais pobre o acesso aos serviços da Psicologia Escolar, estão interligadas às respostas que profissionais e pesquisadores destas áreas possam oferecer aos desafios lançados pelas demandas sociais e educacionais (Souza, 2009).

No enfrentamento das adversidades impostas à escola, sobretudo a pública localizada na periferia das grandes cidades, nosso grupo de pesquisa tem assumido uma perspectiva de investigação e atuação que denominamos Psicologia Escolar Crítica 
tendo em sua base a Psicologia Histórico-Cultural, sobretudo as ideias e conceitos de Vigotski (18961934). Deste lugar do olhar e pensamento reflexivo, desenvolvemos uma forma de atuação nos contextos educativos que se opõe ao modelo clínico, medicalizante, biologizante e patologizante dos sujeitos que interagem nesses espaços, sobretudo nas escolas de Educação Básica, visando à promoção do desenvolvimento, objetivo que deve estar no centro do trabalho da(o) psicóloga(o) na escola.

Essa perspectiva aponta para a prática que adotamos em que se valoriza a importância de uma postura dialógica, reflexiva e integradora do desenvolvimento humano, que considera as condições concretas de vida na escola, entendendo que ações psicológicas que visem a contribuir para esse contexto só podem ser operacionalizadas no e com o coletivo, tendo a parceria com os educadores como mola propulsora dessa atuação que denominamos crítica (Andrada \& Souza, 2015; Barbosa \& Souza, 2015; Souza et al., 2015; Dugnani \& Souza, 2016; Souza, 2016a).

Entendemos a escola como um sistema complexo que envolve várias redes de relações como uma espécie de trama em que se processa o desenvolvimento físico, cognitivo, afetivo e social como dimensões integrantes do psiquismo humano que, por sua vez, se amalgamam às condições do meio físico e social, constituindo a personalidade do sujeito, em um movimento dialético permanente em que concorrem as práticas culturais, socioeconômicas e políticas configuradas pelo sujeito no seu processo de desenvolvimento (Vygotsky, 1927/2004a; 1931/2007). Estes são os fundamentos que sustentam as intervenções de nosso grupo de pesquisa e as reflexões aqui apresentadas, buscando oferecer algumas bases sobre formas de atuação que acreditamos poder contribuir às demandas que se apresentam nas escolas e aos dilemas de muitas psicólogas e psicólogos que nelas atuam.

$\mathrm{O}$ item a seguir apresenta uma breve retomada histórica da incursão da Psicologia na escola. Em seguida, discorremos sobre as bases que fundamentam as práticas psicológicas neste contexto; e finalizamos o texto com algumas considerações sobre os desafios que se impõem a esta área de atuação.

\section{O lugar da Psicologia na escola: breve retomada do percurso e situação atual}

Desde a década de 1980, o trabalho pioneiro de Maria Helena Souza Patto (1984, 1990, 1997) enfatiza críticas ao modelo descontextualizado de atuação de profissionais da Psicologia, voltado, em sua maioria, ao atendimento da queixa escolar tratada como fenômeno unilateral, localizando os problemas do fracasso em um dos polos da relação: ora no aluno - com mais frequência, ora nos professores e/ou nas famílias. Ou seja, não se considera o contexto sociopolítico e econômico, tampouco o sistema de ensino e sua estrutura como constituintes do fenômeno denominado fracasso escolar.

Nos dias atuais, apesar das abundantes e disseminadas críticas à visão individualizante que está na base do trabalho de psicólogas e psicólogos na escola, ainda persistem as práticas clínicas e explicações maniqueístas que envolvem os processos educativos, seja no âmbito das relações ou do ensino e da aprendizagem e seus resultados. E os problemas na escola só se multiplicam, sobretudo aqueles que envolvem conflitos de relações, que têm produzido adoecimento de alunos e professores, conforme demonstram levantamentos divulgados com frequência na mídia. (Guzzo et al., 2010; Souza, 2010; Moysés \& Colares, 2013; Andrada \& Souza, 2015). Ao fazerem essa crítica, as autoras apontam que o objetivo da ação das(os) profissionais de Psicologia é ajustar as(os) estudantes, educadoras(es) e suas famílias ao sistema educacional, entendendo os conflitos dentro das escolas como derivados dos problemas internos da unidade escolar ou das condutas de seus atores.

Persiste, então, como desafio da Psicologia Escolar a proposição e execução de práticas que superem essa visão, tomando a escola como coletivo de sujeitos pensantes que devem se apropriar de suas condições materiais de vida e agir em direção à superação dos problemas que vivenciam. E já estão disponíveis, atualmente, muitas publicações ${ }^{1}$ que narram atuações nesta perspectiva, assim como reflexões sobre conceitos que sustentam essas ações.

Segundo Souza e Andrada (2013), necessário se faz redefinir a forma de atuação das(os) psicólogas(os) nos contextos educativos. Sugerem que, em

${ }^{1}$ O Grupo de Trabalho de Psicologia Escolar e Educacional da Associação Nacional de Pesquisa e Pós-graduação em Psicologia (ANPEPP), que assume essa perspectiva crítica de atuação, já publicou 10 livros reunindo textos das maiores referências em pesquisa e atuação na área. 
primeiro lugar, se reveja os referenciais que têm sustentado as práticas na escola e defendem os fundamentos da Psicologia Histórico-Cultural como mobilizadores da compreensão do ser humano integral, cuja constituição articula as dimensões históricas, culturais e emocionais, em um processo permanente e contínuo, que envolve a apropriação de modos cada vez mais complexos de funcionamento psicológico. Entendem as autoras que essa compreensão permite focalizar o movimento que caracteriza o desenvolvimento como processo revolucionário, valorizando as mudanças do sujeito e do meio, como ação transformadora da própria realidade social que habitam. Quando as(os) profissionais de Psicologias e utilizam de tais premissas, tendem a promover ações favorecedoras do desenvolvimento e emancipação humanos, aspectos estes que adotamos como norteadores de nossos trabalhos nas escolas.

Souza (2009) reafirma a necessidade de se buscar no interior da Psicologia pressupostos teórico-metodológicos que analisem criticamente a relação sujeito-escola, cabendo a esta fazer circular na Educação concepções que embasam o entendimento do homem como produto das relações sociais. Destaca, ainda, que a Psicologia Escolar pede mudanças na forma como se exerce a profissão, que demanda compromisso político por uma escola democrática e de qualidade, o rompimento com concepções normatizantes e adaptativas e a construção de uma práxis psicológica frente à queixa escolar. Para tanto, se requer o resgate da função social da escola conjuntamente com seu papel de difusora do pensamento científico e formadora do sujeito crítico. Também se faz necessário contemplar as dimensões institucional, pedagógica e relacional dos fenômenos que circulam na esfera da Educação.

Refletindo sobre uma atuação crítica voltada à dimensão psicossocial, Sawaia (1995), chama a atenção para a necessária articulação entre teoria e prática, entendida como condição ao desenvolvimento de intervenções que assumam o compromisso político da(o) psicóloga(o) em relação aos contextos sociais em que atua. Nessa articulação, as dinâmicas dos processos histórico-sociais devem ser tomadas como fundamentos dos procedimentos investigativos-interventivos. Exemplo dessa concepção se expressa ao afirmar que as dores em nossa sociedade podem ser interpretadas, no senso comum, como individuais, mas que revelam, na verdade, um sofrimento pro- duzido pelas condições sociais, históricas e ideológicas que perpassam e constituem os sujeitos em suas realidades de vida. Para a autora, é desta perspectiva que deve partir a atuação de psicólogas e psicólogos comprometidos com a transformação do sujeito e da realidade em que se inserem, a qual constituem e pela qual também são constituídos (Sawaia, 2010).

Apenas por essa via pode-se projetar a possibilidade transformadora e emancipatória dos sujeitos envolvidos em tal processo. Neste sentido, a(o) psicóloga(o) surge com um papel de agente político, responsável pela transformação da realidade e promoção de desenvolvimento (Sawaia, 1995, 2010).

Mas, como colocar tais premissas em prática? Afinal, o que faz a(o) psicóloga(o) nos contextos educativos? Tentar responder a essas questões é o que se apresenta nos próximos tópicos deste artigo.

\section{Os passos para a construção das ações na escola}

O Conselho Federal de Psicologia (CFP), em suas Referências Técnicas para Atuação de Psicólogas(os) na Educação Básica (2013), apresenta sugestões de ações a serem desenvolvidas. Aponta, primeiramente, o trabalho a ser realizado com o projeto político-pedagógico da unidade, em sua construção e execução; em segundo, a intervenção no processo de ensino e de aprendizagem; e ainda, atuações na formação de educadores e com grupos de alunos, assim como com a educação inclusiva. $\mathrm{O}$ referido documento sugere também que esta(e) profissional deva ter o conhecimento das Políticas Públicas nacionais e regionais, além do contato com Secretarias e outros órgãos que regem a Educação.

Pensamos que os conceitos vigotskianos oferecem subsídios para uma ação em consonância com o que propõem as orientações do CFP. É nesse sentido que vimos defendendo que teoria e prática constituem uma unidade indissociável, visto que se imbricam e se retroalimentam permanentemente. A um só tempo, são produtoras e produto da intencionalidade do profissional que atua em contextos educativos. Logo, os pressupostos deste autor sustentam também nossas práticas profissionais.

Ao adentrarmos a escola, tal como preconiza Vygotsky (1927/2004a), tomamos a realidade como misteriosa, compreendendo que cada instituição se constitui de forma singular, por meio da relação entre as condições concretas de atuação e das inte- 
rações entre professores, alunos, gestores, membros das secretarias de educação e comunidade, e que é no movimento dessas tramas relacionais que a realidade vai se configurando e se transformando. Relevante se faz, portanto, a aproximação de cada um dos grupos da escola, dando voz aos sujeitos, buscando acessar suas expectativas em relação às possíveis contribuições da(o) psicóloga (o) (Petroni \& Souza, 2014; Andrada \& Souza, 2015; Barbosa \& Souza, 2015; Souza et al., 2015; Dugnani \& Souza, 2016; Souza \& Luz, 2017).

Essa forma de atuar em nosso grupo, decorre da necessidade de se compreender as bases de constituição do fenômeno investigado e/ou objeto da ação interventiva e construir ações coletivas para transformar seu curso, sua intensidade e seu conteúdo.

Essa premissa decorre de nossa compreensão da escola como um microcosmo do social, cujas relações que caracterizam os seus modos de funcionamento são apropriadas da cultura e historicamente construídas. Han (2015), filósofo germano-coreano, em seu livro "Sociedade do Cansaço", afirma que os modos de relação na contemporaneidade são compreendidos segundo os pressupostos da lógica neoliberal, sendo marcados pela imperatividade do desempenho e medidos pela capacidade de o indivíduo atender a amplas e diversas demandas de modo quase imediato.

Nesta lógica, os tempos para reflexão são considerados um entrave à eficácia e à eficiência, uma vez que é imperativo agir para produzir. O resultado tem sido um número cada vez maior de pessoas esgotadas, que são perversamente culpadas pela sua situação e apontadas como ineficazes e ineficientes. $\mathrm{O}$ medo dessas acusações faz com que os sujeitos abram mão, muitas vezes de bom grado, dos espaços coletivos que lhe permitiriam transformar e superar estas condições (Han, 2015)

Segundo o que temos observado, esta também parece ser a tônica na escola. O sistema educacional, ano após ano, imputa novas atribuições a seus profissionais. O grupo de pessoas sob a responsabilidade dos professores e dos gestores torna-se cada vez mais numeroso, o que faz com que sejam constantemente solicitados a dar encaminhamentos imediatos e simultâneos a eventos das mais diferentes naturezas. Além das demandas do cotidiano escolar, apresentam-se também as exigências das instâncias governamentais de preenchimento de documentos, alimentação de bases de dados nos sistemas oficiais, aplicação de avaliações nacionais e regionais, convo- cação para comparecimento a reuniões, dentre outros (Dugnani \& Souza, 2011; Petroni \& Souza, 2014; Dugnani \& Souza, 2016).

Como vimos pontuando em nossos estudos, parece que essas condições materiais de trabalho têm resultado em um modo de funcionamento da escola que se caracteriza como ações pontuais, voltadas aos problemas imediatos, sem possibilidades de reflexão ou planejamento. De nossa perspectiva esse modo de funcionar da escola que impede a reflexão sobre a ação está na base da aparente "não mudança" apontada em muitos estudos sobre a educação escolar (Dugnani \& Souza, 2011; Petroni \& Souza, 2014; Dugnani \& Souza, 2016).

Nesse movimento caracterizado por um pragmatismo que aparentemente dá conta dos problemas que aportam na escola é preciso destacar, ainda, a falta de investimento em espaços coletivos promotores de desenvolvimento, como por exemplo, a formação continuada de professores, que, por vezes, tem como conteúdo discussões de questões organizativas e burocráticas. Na vivência dos professores, muitas vezes esgotados com as demandas para além do ensino e com as precárias condições de trabalho passam a conceber a formação em exercício como algo dispensável, e as possibilidades de avançar a reflexão rumo à superação da naturalização dos processos educativos e das condições de trabalho na escola ficam limitadas (Andrada \& Souza, 2015).

Radica nesta compreensão nossa proposta de atuação da(o) psicóloga(o) nos espaços de formação continuada na escola: na promoção da reflexão, na superação de modos de pensar, ser e agir na importante e fundamental função de formar crianças e jovens. Ações que se voltem à construção e manutenção de espaços que favoreçam a expressão e reflexão dos sujeitos, desvelando as contradições que constituem o cotidiano da escola, como forma de assumir a sua responsabilidade nos processos educativos, por um lado, e a de implicar os demais atores, intra e extramuros da escola na construção de uma educação pública de qualidade, por outro (Dugnani \& Souza, 2011; Souza et al., 2015; Dugnani \& Souza, 2016)

Nesse movimento nos valemos de um precioso pressuposto de Vinha e Welcman (2010), que orienta a construção de nossas intervenções na escola: a necessidade de promover situações sociais de desenvolvimento (SSD) favorecedoras de vivências, e temos observado que a utilização da arte como instrumento 
de mediação da cultura resulta na configuração de SSD, sobretudo com os educadores, por gerar ricas e profícuas reflexões sobre suas vidas pessoais e profissionais (Souza et al., 2018).

Compreendemos vivência como um tipo de experiência que tem no centro as emoções e promove a configuração de novas significações pelo sujeito em relação ao que está vivendo no momento (Vinha \& Welcman, 2010). Ela promove o desenvolvimento da consciência, visto ampliar as possibilidades de significação e produzir novos nexos entre as funções psicológicas. SSD e vivência formam uma unidade indissociável do desenvolvimento humano, pois se constituem mutuamente em um movimento dialético que integra as dimensões do sujeito e do meio.

É a relação entre SSD e vivência que pode favorecer mudanças nos modos como os pensamentos e ações se objetivam na escola, podendo resultar em novas formas de sentir, pensar e agir, neste contexto (Vinha \&Welcman, 2010; Roth \& Jornet, 2016). A proposta que adotamos é que devemos visar à promoção de vivências na escola como forma de intervir nas condições apresentadas, sobretudo para a desnaturalização dos processos e concepções em relação ao ensino, aos alunos, às famílias, à educação escolar e não escolar, enfim (Andrada \& Souza, 2015; Souza, 2016a).

Desse modo, podemos compreender o sujeito enquanto ator e autor do seu próprio desenvolvimento. Ator porque, por um lado, este processo está condicionado pelas relações concretas a que está submetido, atuando a partir e sobre elas; e autor porque, por outro lado, se relaciona de modo singular, configurando significados e atribuindo sentidos a estas interações, constituindo-as e constituindo seus modos de se relacionar com o mundo (Vinha \& Welcman, 2010; Andrada \& Souza, 2015; Roth \& Jornet, 2016; Souza, 2016a).

Importa chamar a atenção para um aspecto da maior relevância que, muitas vezes, emperra o trabalho da(o) psicóloga(o) na escola: o fato de se ter uma proposta crítica de atuação, sustentada por perspectivas que focalizam o social e as relações, tendo como princípio o respeito à história dos sujeitos, à cooperação e à emancipação, não garante a possibilidade de levá-las adiante. É preciso considerar que a adesão ao trabalho é um desafio inicial e permanente, que passa pela construção de vínculos de confiança com educadores e alunos que, por sua vez, só é possível pelo diálogo e explicitação clara da intencionalidade das práticas psicológicas ( Souza, 2016a).

É preciso explicar a diferença entre essas práticas - que visam as relações, o afetivo, o desenvolvimento do sujeito - das práticas de ensino, que também visam o desenvolvimento, mas por meio da apropriação de conhecimentos formais, disciplinares e de convivência. A explicitação da diferença de INTENCIONALIDADES entre estas duas formas de atuação, é o primeiro passo para viabilizar a parceria entre educadoras(es) e psicólogas(os). Trata-se de um processo de construção permanente porque os questionamentos, as resistências e contradições são constituintes das relações e devem ser acolhidos e refletidos, quando se pretende desenvolver uma práxis (Vinha \& Welcman, 2010; Souza et al., 2015; Roth \& Jornet, 2016; Souza, 2016a; Souza, 2016b).

Destacamos a seguir o papel do coletivo no desenvolvimento de práticas críticas na escola.

\section{A(0) psicóloga(o) escolar na construção da coletividade na escola}

A escola é um espaço marcado historicamente pela diversidade de sujeitos que nela aportam, tais como: alunos, professores, gestores, pais, funcionários da secretaria, equipe de limpeza, profissionais da secretaria de ensino, dentre outros. Contudo, o compartilhamento de um mesmo espaço por diversos sujeitos, que exercem diferentes papéis, não garante a constituição da coletividade.

Isso porque a coletividade não está dada $a$ priori, mas trata-se de um processo histórico, em que:

O fator que transforma o grupo em uma coletividade é a atividade conjunta de seus membros, uma atividade socialmente significativa e que responda, a um só tempo, as demandas da sociedade e aos interesses da personalidade, superando assim a contradição entre o individual e o grupal (Petrovsky, 1984, pp. 8-9, tradução nossa).

Também é nessa direção que Lane (1989) defende a ideia de se compreender não o grupo, mas o processo grupal, o que implica dizer que é preciso desvelar as condicionantes históricas e materiais que fizeram aquela equipe chegar a ser o que é, para que se possa superar os desafios que se impõem ao cotidiano na escola. Para a autora, todo grupo vive a contradição 
entre a reprodução das formas de relação do status $q u o$, sustentadas pela lógica capitalista, pautada nas ideias de culpabilização dos indivíduos pelos "resultados não alcançados", e a possibilidade de se produzir novas formas de ser, pensar e estar no mundo.

Fica evidente que o funcionamento do grupo é análogo ao que Marx e Engels (1989) afirmam ser o movimento do desenvolvimento: do mesmo modo que o homem ao modificar a natureza modifica a si mesmo, em movimento dialético permanente, o sujeito ao atuar no grupo o constitui e o modifica ao mesmo tempo em que é constituído e modificado por ele. A coletividade é, portanto, resultado do trabalho humano, possibilitada por espaços que permitam aos envolvidos construir e compartilhar valores, visão de mundo, de sujeito, e objetivos comuns, que sejam socialmente significativos para todos e para cada um dos membros do grupo, bem como para os demais grupos da sociedade que esta coletividade se relaciona (Petrovsky, 1984; Lane, 1989; Dugnani \& Souza, 2016).

Este desafio se mostra especialmente complexo quando se trata de escolas públicas. Embora se alardeie aos quatro ventos a importância da Educação para a transformação social, o que se vê, atualmente, parece favorecer o desmonte de suas bases, relegando-se às camadas mais pobres da população instituições de ensino cada vez mais precárias. Esse mecanismo perverso resulta no pouco domínio dos alunos dos conteúdos escolares ${ }^{2}$, no adoecimento de professores e gestores, na desvalorização do acesso à educação como ferramenta de transformação e no tensionamento das relações na escola (Libâneo, 2012; Fernandes, 2015). O que fazer diante de um cenário tão desolador? É possível construir a coletividade em um ambiente tão adverso?

Pensamos que sim; mais do que possível, vemos a coletividade como potencial forma de superação das condições perversas e alienantes impostas pelo sistema político-econômico à educação pública (Petrovsky, 1984; Lane, 1989; Charlot, 2013). Como afirma Lane (1989), o primeiro trabalho de um coletivo é constituir-se como tal. É aqui que pensamos que a Psicologia pode contribuir: a criação e manutenção de espaços que levem os diversos atores escolares a questionarem e refletirem sobre as bases da escola. Que escola temos? Que escola queremos? O que podemos fazer para construir esta escola? Quais são nossas possibilidades e limites? Qual é o tom das relações interpessoais na escola?

O que queremos evidenciar neste texto e em nossas intervenções é que é preciso criar situações para que as contradições sejam acessadas pelo grupo e possam ser configuradas em um processo de desenvolvimento de consciência coletiva. As contradições são forças motrizes dos processos grupais e das mudanças, pois podem levar o grupo a um movimento em espiral, em que concorrem acordos e desacordos, congruências e incongruências, criando a necessidade de se construir sínteses em que todos e cada um se reconheçam como constituídos e constituintes da e na realidade (Lane, 1989). Nas palavras da autora "as contradições são as sínteses dos diversos” (p. 82).

Os momentos de tensionamento, divergências e resistências, são partes necessárias deste processo, já que sujeito e grupo são convidados, a um só tempo, a saírem de si e olharem para os outros e a serem olhados pelos outros. De nossa perspectiva, a coesão e harmonia irrestrita de um grupo é algo preocupante, pois revela a falta de questionamento, de incômodos, de reflexão, que são condição para a mudança como demonstrado em Dugnani e Souza (2016).

Com vistas a contemplar tamanho desafio, procuramos em nossos trabalhos, focar nos processos relacionais, mediar os diálogos, de modo que o grupo seja capaz de ouvir e acolher as divergências, as contradições e as concordâncias. Saber lidar e conduzir os momentos de tensão, as discussões, as tentativas de impor sua opinião sobre os demais, as disputas de poder, enfim, promover espaços reais de fala e escuta são, em última instância, papéis da(o) psicóloga(o) na construção da coletividade.

\section{Promoção de espaços de fala e escuta: base de construção do coletivo na escola}

Inspirados por algumas pesquisas (Souza \& Andrada, 2013; Souza, Dugnani, Petroni, Andrada \& Barbosa, 2013b; Andrada \& Souza, 2015; Dugnani

\footnotetext{
${ }^{2}$ No dia 25 de outubro de 2017, o jornal Folha de S. Paulo publicou os resultados da Avaliação Nacional de Alfabetização (ANA), aplicada em alunos do $3^{\circ}$ ano do Ensino Fundamental da rede pública de ensino, que revelam que 54,5\% dos alunos, desse ciclo da escolarização, não conseguem resolver contas simples de matemática, e tampouco identificar e interpretar textos da literatura infantil. Disponível em: http://www1.folha.uol.com.br/educacao/2017/10/1930040-metade-dos-alunos-de-8-anos-tem-nivel-insuficiente-de-leitura-e-matematica.shtml
} 
\& Souza, 2016; Souza, 2016a), muitas intervenções promovidas pelo grupo ao qual nos filiamos revelam que, fundamentalmente, devemos investir no diálogo como espaço de expressão dos sujeitos, abrindo a possibilidade de ressignificação das experiências vividas no interior da escola.

Segundo Souza e Andrada (2013), os exercícios da fala e da escuta promovem a reconfiguração de sentidos e significados das experiências no contexto institucional. Vygotsky (1934/2010) esclarece que o pensamento se realiza na palavra, veículo de expressão do predicado psicológico permeado de afetos; pontua que é a fala/palavra que faz a mediação dos nossos processos internos como uma espécie de ponte para acessar a subjetividade humana. Pela dialogia, tomamos a fala como condutora de sentidos e significados erigidos na e pela intervenção da(o) psicóloga(o), mas não qualquer forma de fala, e sim a constituída por palavras que aglutinam os sentidos internos do sujeito.

Viabilizamos este espaço de dialogia por meio de rodas de conversas com integrantes da escola: alunos, professores, diretores, coordenadores pedagógicos, familiares, grupos comunitários. As reuniões de troca de informações que fazem parte da rotina da escola, assim como a observação dos ambientes formais e não formais (corredores, refeitórios) são, também, ricas fontes de trocas (Petroni \& Souza, 2014; Andrada \& Souza, 2015; Barbosa \& Souza, 2015; Souza et al., 2015; Dugnani \& Souza, 2016; Souza \& Luz, 2017).

A esse respeito, as referências técnicas do Conselho Federal de Psicologia - CFP (2013) sugerem a adoção de espaços de diálogos com alunos e educadores sobre temas atuais que afetam o cotidiano da escola: adolescência, sexualidade, (des)valorização da escola, transição de ciclos, disciplina e indisciplina, violência, questões de gênero, desigualdade social, preconceito, discriminação. Corroboramos a recomendação e afirmamos que essas ações devem ser planejadas, inseridas em um projeto maior que declara a intencionalidade da intervenção, que não deve se caracterizar como pontual, modo por vezes adotado em estágios de Psicologia nas escolas, mas que precisa produzir movimentos reflexivos e apoiar os educadores para que deem continuidade à reflexão sobre esses temas.

Esse lugar da(o) psicóloga(o) como apoiador e facilitador do processo reflexivo é uma das premissas básicas das ações que defendemos em que se busca compreender as necessidades dos participantes, aco- lher as suas reivindicações, atuar como uma ponte em uma rede de múltiplas relações no apoio à resolução de problemas cotidianos e, ainda, incorporar à rotina da escola estes momentos de diálogo e trocas. Daí a defesa de que é um trabalho permanente, longo, processual, construído por meio de encontros com os diferentes grupos da escola (Souza, 2016a).

\section{Os afetos como alvo de ação da(o) psicóloga(o) na escola}

Se há consenso de que o papel da(o) psicóloga(o) na escola é de mediador, cabe perguntar: mediador do quê? E a resposta seria: mediador das relações. Mas ocorre que os gestores e professores também o são, visto que atuam cotidianamente com grupos e necessitam intervir nas interações entre os diversos atores escolares para viabilizar a convivência nesses espaços (Petroni \& Souza, 2014).

Então o que seria específico da(o) psicóloga(o)? Esta é uma questão que nos é colocada recorrentemente nos cursos de Psicologia, fóruns de discussão sobre o tema, e nas escolas em que desenvolvemos nossos trabalhos, e respondê-la tem sido uma busca permanente de nosso grupo de pesquisa. Para isso temos trilhado um duplo caminho: ampliar nossa compreensão sobre o papel das emoções e dos afetos na constituição dos modos de relação dos sujeitos com o mundo; e construir práticas que promovam a sua expressão e transformação, visando o aumento da potência de ação dos atores escolares, rumo à superação das condições concretas que causam seu sofrimento e adoecimento.

Sawaia (2009) afirma que as(os) profissionais de Psicologia, muitas vezes por medo de serem acusadas(os) de psicologismo, acabam se esquivando de investigações e intervenções que tenham as emoções e os afetos em seu cerne. Este afastamento decorre de uma visão hegemônica, que ainda persiste na Psicologia, de que as emoções são privativas dos indivíduos, concepção fortemente contestada pela Psicologia Histórico-Cultural.

Os afetos, compreendidos a partir de Spinoza (1677/2010), como a capacidade de afetar e ser afetado, estão na base da constituição dos modos de relação do sujeito com o mundo. É neste sentido que Vinha e Welcman (2010) afirma que o meio é FONTE de desenvolvimento e não fator. Fonte porque tensiona concomitantemente a manutenção e a transformação dos modos históricos, culturais e socialmente 
construídos de afetar e ser afetado, contudo, o sujeito como ser ativo que é, tem a capacidade de significar e ressignificar as vivências e as emoções que decorrem destas afecções, desde que estes processos sejam favorecidos. O que se nota é um movimento dialético permanente e indissociável entre sujeito e meio, em que não é possível demarcar com exatidão em que medida cada um constitui e/ou é constituído pelo outro, evidenciando o caráter coletivo, datado e histórico dos afetos e das emoções (Souza \& Andrada, 2013; Souza, Petroni \& Andrada., 2013a; Souza et al., 2013b; Andrada \& Souza, 2015; Dugnani \& Souza, 2016).

Spinoza $(1677 / 2010)$ ressalta que conhecer a natureza das afecções pode resultar na transformação qualitativa das emoções que delas decorrem e aumentar a potência de ação dos sujeitos, colocando-os em movimento. No contexto escolar, isto significa conhecer os ideários neoliberais que fundamentam as atuais diretrizes da Educação Básica e que buscam responsabilizar os indivíduos pela sua precarização e fracasso; reconhecer as dificuldades que se impõem na contemporaneidade à construção de uma escola pública de qualidade; compreender a complexidade como fator constituinte do espaço escolar, visto que nela aportam conflitos e contradições da sociedade em que está inserida; e a constituição da coletividade como condição para tensionamentos que podem contribuir para a realização das transformações possíveis.

É nesta dimensão do desenvolvimento que a(o) psicóloga(o) deve atuar, intervindo no meio, sobretudo nas relações de modo a favorecer vivências que ampliem a consciência sobre as possibilidades e limites de transformação das condições materiais de existência pelo coletivo escolar, compreendido aqui de modo amplo, composto pelos atores intra, inter e extramuros da escola. É neste sentido que vimos defendendo, assim como outros autores, que afetos e emoções são dimensões a serem trabalhadas, refletidas, vividas. E ao vivê-las e significá-las, incorporando seu potencial na promoção do desenvolvimento, pode promover o conhecimento de si, do outro e das condições materiais a que se está submetido (Souza \& Andrada, 2013; Souza et al., 2013a; Souza et al., 2013b; Andrada \& Souza, 2015; Dugnani \& Souza, 2016).

As possibilidades de viver as situações de outros modos, a identificação do que é responsabilidade de cada sujeito e instância, intra, inter e extramuros da escola, por meio da reflexão sobre o que se sente e se vive, sempre em grupo e com o apoio da(o) psicólo- ga(o), pode configurar novos sentidos e significados em relação às situações cotidianas, e romper com as visões naturalizantes, individualizantes e culpabilizantes, que muitas vezes estão na base dos motivos que levam os atores escolares a padecerem, na medida em que desmobiliza o coletivo diminuindo a potência de ação dos sujeitos e do grupo (Sawaia, 2009; Andrada \& Souza, 2015).

Assumimos neste contexto um papel de mediador na promoção de reflexões sobre os modos de pensar e agir dos sujeitos, sobre como esse modo afeta a si próprio e ao outro, oferecendo abertura para trocas que garantam a expressão de pensamentos e emoções, contemplando a diversidade de opiniões, de formas ser e agir, tendo o diálogo como base do fortalecimento das relações.

Assim como apontado por Souza (2016a, p. 89):

O psicólogo "não ensina" na escola; ao contrário, ele aprende e apreende os sentidos e significados que circulam nas relações e "promove a reflexão" sobre eles, assumindo o papel de "mediador dos afetos", entendidos como modo de viver, sentir, perceber a realidade, utilizando-se de conhecimentos, estratégias e técnicas apropriados [...].

A escola apresenta-se como um contexto complexo, permeado e constituído pelos conflitos que se dão nas relações estabelecidas entre esses atores, em que os afetos presentes na base dessas ações não são nomeados, e seus significados e sentidos não são reconfigurados. Importa ainda, a título de últimas considerações sobre a importância de se olhar e promover espaços de expressão de afetos na escola como potentes na transformação das relações, chamar a atenção para a dimensão coletiva necessária a essa construção. Muitas vezes os afetos são compreendidos como individuais, dizendo respeito a cada um, e não como base de ações que, se coletivas, ampliam imensamente o poder de agir do grupo como um todo.

O que se quer afirmar é que a escola pode se constituir como um espaço promotor de vivências de modos mais elaborados de relações. Sawaia (2010) afirma que o sofrimento ético-político decorre da dor de ser reconhecido como um ser descartável, de menor valor, sem importância. Assim, defendemos que a ampliação da consciência sobre os afetos e as emoções que condicionam os modos de relação na 
escola pode transformar o sofrimento e o padecimento, em potência de ação. Em um mundo em que a intolerância, a violência e a discriminação ainda permanecem, a escola pode se constituir como um espaço de organização coletiva na luta pelo respeito à diversidade, pela garantia à equidade, por melhores condições de trabalho, de vida e de educação de todos os seus atores, possibilitando a construção de modelos mais humanizados de se relacionar no e com o mundo, e negando a alcunha de cidadão de segunda categoria que o descaso do poder público tem relegado à escola dos pobres (Libâneo, 2012).

Essas são demandas dirigidas à(ao) psicóloga(o), e atuar buscando atendê-las requer uma formação sólida, com compreensão clara do contexto educacional como um todo e da escola em particular; da forma como o desenvolvimento se processa e um compromisso e disponibilidade para investir, permanentemente, em modelos de ação que se aproximem dessas queixas. Essa mediação que reporta à(ao) psicóloga(o) não se confunde com a dos educadores, justamente pela especificidade de conhecimentos e atuações que a caracterizam.

Nesse caminho, temos empreendido esforços no desenvolvimento de ações que façam emergir os afetos e as emoções que estão na base dos modos de relações estabelecidos entre sujeitos, e a arte tem se revelado como uma importante ferramenta em nossas intervenções.

\section{A arte como materialidade que favorece a expressão de afetos}

Vygotsky (1925/2001), em sua tese de doutorado, que resultou na publicação do livro intitulado "Psicologia da Arte", revela o seu potencial como mediadora do processo de autoconhecimento e desenvolvimento dos afetos. Afirma ser possível adentrar e transpor questões relativas ao humano por meio do sensível, uma vez que a arte desperta emoções outrora ocultas, nos liberta dos recalques, promovendo uma reorganização de nossa conduta, já que tem em si o potencial de nos orientar e nos motivar. Sugere o autor que podemos favorecer a elaboração de emoções e sentimentos pelas variadas manifestações artísticas: por meio da apreciação de expressões como, música, literatura, teatro, artes visuais, dança e cinema, temos a possibilidade de acessar nossos afetos, organizá-los e dominá-los, não no sentido de autocontrole, mas de compreensão do que se sente e se pensa.
Em nosso trabalho interventivo, ao usarmos as materialidades artísticas, buscamos ir além do evidente, encontrar o que toca o sujeito para proporcionar sua reflexão sobre o que vivencia em seu cotidiano, para saber-se de si e do outro, de suas reais condições de existência. Podemos encontrar exemplos que corrobora esse modo de atuação nas já citadas referências técnicas do Conselho Federal de Psicologia - CFP (2013), em que se destaca o uso de mediadores culturais (música, teatro, desenho, dança, literatura, cinema, grafite) como aporte às intervenções na escola.

Temos denominado a arte como materialidade mediadora respaldada no trabalho de Souza, Petroni e Dugnani (2011), pois estamos falando de símbolos produzidos pelo homem e que constituem sua cultura, por isso materialidades; e mediadoras por possibilitar que os sujeitos sejam acessados quando se expressam, favorecendo o desenvolvimento da consciência de si e do outro, de sua imaginação, sua vontade, enfim, de seu sistema psicológico. A nosso ver, essa definição se aproxima do proposto por Ianni (2004, p. 12), ao defender que a arte se apresenta como revelação:

As narrativas literárias e de outras linguagens artísticas, no entanto, contribuem principalmente para o que se pode denominar revelação [grifo do autor], desvendamento da realidade e do imaginário, o visível e o invisível, o prosaico e o surpreendente, implicando uns e outros, indivíduos e coletividades, povos e nações, em diferentes épocas, surpreendendo o querer e as volições nas quais indivíduos se movem ou são movidos, como atores ou títeres de inquietações que podem ser fugazes ou de forças sociais que podem ser avassaladoras.

Conforme colocado por Souza (2016b), a utilização da arte nas práticas da Psicologia Escolar possui uma intencionalidade com relação ao seu objeto de ação que é o desenvolvimento do sujeito na medida em que coloca o fenômeno em movimento possibilitando o desenvolvimento das funções psicológicas superiores. Isto porque a emoção que está no centro das obras artísticas é vivida pelo sujeito como real na mediação produzida pela materialidade (música, dança, fotografia, pintura, escultura, histórias), e desencadeia o movimento entre as funções psicológicas superiores na pro- 
dução de novos nexos, que configuram novos modos de agir e ser do sujeito. Essa experiência com a arte se constitui no que Vygotsky (1925/2001) denomina de vivência estética, pela qual meio e personalidade se fundem e o desenvolvimento se consolida.

Isso se dá porque a forma e o conteúdo da obra constituem uma unidade de sentido e de significado, o que une personalidade e meio na vivência estética, possibilitando a (re)configuração de novos nexos, relacionando-se de forma direta com as emoções que se encontram na base da vivência (Cassirer, 1977; Vygotsky, 1925/2001).

Por meio da arte o sujeito vivencia diferentes afetos e emoções que podem ser materializados via expressão do que se sente e pensa, pela imaginação ou ato criador. Segundo Vygotsky (1925/2001), é o aspecto social da arte que se inscreve no sujeito; lembrando que este não é sinônimo de coletividade pois, mesmo quando sozinho, o homem encontra-se inserido em uma sociedade e em uma cultura, já que carrega em si as marcas ontológicas de sua história. Partindo da realidade que se apresenta, a arte modifica, representa, cria e recria algo que pode não ser diretamente nela encontrado, revelando dessa forma, o sentimento particular do indivíduo, mas que por meio dela objetiva-se, tornando-se social.

Assim, temos investido na apreciação de diferentes expressões artísticas (música, fotografia, pintura, escultura, contação e produção de histórias, filmes, documentários, poesias, literatura) e, algumas vezes, também na produção de desenhos, pinturas, poesias, músicas, documentários, contos, e esculturas como forma de legitimar espaços em que os diferentes atores escolares (alunos, professores, gestores) expressem, acessem e repensem seus afetos, suas práticas e suas relações, buscando a promoção de movimentos em que esses sujeitos se constituam como atores e autores de suas narrativas, de suas histórias.

\section{Investir no potencial de ação dos sujeitos}

Olhar para as práticas possíveis da(o) psicóloga(o) escolar tendo como alvo o desenvolvimento humano e fundamentada nos pressupostos de Vigotski, nos encaminha para algo que parece ser o mais belo aspecto colocado por essa teoria: a crença no potencial de ação dos sujeitos, o qual se sustenta nas concepções de Marx e Espinosa.

Sawaia (2009) nos ajuda na compreensão de como esses teóricos influenciaram Vigotski na cons- trução do sistema psicológico e como suas funções se unem em nexos que possibilitam o desenvolvimento, assim como na visão monista dos sujeitos e a importância de se considerar os afetos nesse processo. Ao compreender os sujeitos e seu modo de funcionar nessa perspectiva, somos impulsionados e dirigidos a buscar aprender e apreender que no sofrimento, na falta, na deficiência e na dificuldade também são encontradas as possibilidades de se investir nas potencialidades. Como pontua a autora:

É uma perspectiva analítica que entende que por trás da desigualdade social há vida, há sofrimento, medo, humilhação, mas também há o mais extraordinário milagre humano: a vontade de ser feliz e de recomeçar ali onde qualquer esperança parece morta. Há, portanto, o homem por inteiro, de corpo e mente, emoção e razão, determinado e determinante da sociedade, de forma que o que acontece com um afeta o outro (Sawaia, 2009, p. 365).

Traduzir essas acepções para o contexto escolar permite dizer que a Psicologia Histórico-Cultural compreende o "aluno que fracassa" como alguém capaz de aprender, de ser criativo, com potencialidade de transformar sua realidade. $\mathrm{O}$ mesmo vale para o educador resistente, desanimado, e descompromissado, que tem potencial para transformar sua vida, suas condições materiais de trabalho, suas ações e é desta perspectiva que buscamos pautar nossas intervenções.

Para tanto, é importante não nos centrarmos naquilo que a criança, o jovem ou o adulto "não sabe", o que lhe "falta", mas buscar desvelar seu potencial e agir oferecendo ajuda pela mediação da cultura. Esta é a dinâmica do desenvolvimento, e a escola, segundo esta visão, tem papel fundamental em sua promoção. Eis aqui outra contribuição que a Psicologia Escolar pode oferecer aos educadores: a explicitação do processo de desenvolvimento e sua dinâmica, de modo que possam pensar ações para promovê-lo. Diz Vygotsky (1930/2004b) que os mediadores culturais (a língua, os numerais, a arte, entre outros) se convertem em instrumentos que acedem ao psiquismo e provocam desenvolvimento: "ao inserir-se no processo de comportamento, o instrumento psicológico modifica de forma global a evolução e a estrutura das funções psíquicas, e suas propriedades determinam a configuração do novo ato instrumental" (p. 94). 
Sawaia (2009) nos traz outra perspectiva do que seria trabalhar para o desenvolvimento do potencial de ação do sujeito embasada na teoria de Spinoza e Vigotski. Ela sustenta a ideia de sujeito que se constitui nas determinações sociais, mas como dimensão de superação de suas condições de vida e não o de desistência, conferindo grande importância à dimensão afetiva-volitiva. Diz a autora que investir no potencial de ação do sujeito possibilita a passagem da passividade à atividade e realça o papel positivo das emoções na conscientização e desenvolvimento humano em que as emoções não representam fonte de desorganização, mas fator impulsionador deste potencial.

Desta perspectiva é possível pensar que promover o desenvolvimento de potencialidades na escola implica compreender que os atores escolares possuem condições de expandir seus limites uma vez conscientes das dimensões que mobilizam suas ações e possibilidades, ou seja, o afetivo-volitivo que deve ser alvo de ação da(o) psicóloga(o).

Esses apontamentos nos remetem aos princípios éticos que fundamentam os pressupostos de Vigotski, de acordo com Delari (2009): a superação, a cooperação e a emancipação. A superação diz respeito à capacidade de ir além dos limites, buscando nas condições materiais de existência as possibilidades para transformar a realidade. Já a cooperação apresenta-se como elemento fundamental nesse processo, na medida em que é na e pela relação com o outro, no cooperar, que se torna possível a constituição do humano e, por último, a emancipação, considerada conquista máxima do homem, que se dá pela autonomia exercida no coletivo, isto é, quando há o desenvolvimento de sua liberdade, por meio do conhecimento e do reconhecimento de seu papel no e pelo social (Dugnani \& Souza, 2016; Barbosa, 2017).

Nesse processo, procuramos respaldar nosso trabalho no compromisso com uma reflexão crítica per- manente, que tem o respeito pelo outro e a aposta em suas possibilidades como centrais, tomando o coletivo como espaço de atuação.

\section{Algumas considerações sobre os desafios da área}

Ainda hoje encontramos dificuldades em ter reconhecido o espaço a ser ocupado pela(o) psicóloga(o) dentro da escola, como profissional que faz parte da equipe técnica deste contexto. Reproduz-se, em todos os níveis de escolarização, o despreparo e as dificuldades para que a Psicologia possa ser ferramenta de promoção do desenvolvimento de educadores e educandos - sem políticas públicas para o ingresso dos profissionais de Psicologia na rede pública de ensino, cada vez mais, esse cenário de desigualdade tende a se ampliar (Guzzo et al., 2010; Souza, 2010).

É preciso que nosso olhar, enquanto formadores, pesquisadores e atuantes na área da Psicologia Escolar também se transforme, a começar pelo nosso engajamento na luta pela defesa do psicólogo na escola e no combate às formas de atuação que tomam por base a queixa escolar centrada no aluno ou suas famílias. Não se trata de individualizar a resolução das demandas, mas criar um espaço em que seja possível a ampliação da consciência de todos sobre sua responsabilidade nos processos de ensino e de aprendizagem.

É no coletivo que se torna possível a construção de uma prática psicológica que contribua efetivamente para o desenvolvimento de todos os envolvidos com a escola. E investir na formação de profissionais capazes de mediar a construção desse coletivo e atuar nos grupos e com os grupos equivale a assumir-se como profissionais compromissados com a educação e a escola, espaços que se caracterizam, eminentemente, como sociais e coletivos. E considerar as dimensões apontadas neste texto é um caminho para se repensar a formação em Psicologia Escolar.

\section{Referências}

Andrada, P. C., \& Souza, V. L. T. (2015). Corpo e docência: A dança circular como promotora do desenvolvimento da consciência. Revista Psicologia Escolar e Educacional, 19(2), 359-368. https://doi.org/10.1590/2175$3539 / 2015 / 0192855$

Antunes, M. A. M. (2008). Psicologia escolar e educacional: História, compromissos e perspectivas. Psicologia Escolar e Educacional, 12(2), 469-475. https://doi.org/10.1590/S1413-85572008000200020

Barbosa, E. T. (2017). Os "donos da imaginação": A contação e produção de histórias promovendo o interesse e a participação de adolescentes em atividades escolares (Tese de doutorado). Pontifícia Universidade Católica de Campinas. Campinas, SP, Brasil. Recuperado de: http://tede.bibliotecadigital.puc-campinas.edu.br:8080/jspui/handle/tede/952 
Barbosa, E. T., \& Souza, V. L. T. (2015). Sentidos do respeito para alunos: Uma análise na perspectiva da psicologia histórico-cultural. Psicologia: Ciência e Profissão, 35(2), 255-270. https:// doi.org/10.1590/1982-370300462013

Cassirer, E. (1977). Antropologia filosófica: Ensaio sobre o homem. São Paulo, SP: Mestre Jou.

Conselho Federal de Psicologia - CFP. (2013). Referência técnicas para atuação de psicólogas (os) na educação básica. Brasília, DF: o autor. Recuperado de: http://site.cfp.org.br/publicacao/referencias-tecnicas-para-atuacao-de-psicologas-os-na-educacao-basica/

Charlot, B. (2013) O professor na sociedade contemporânea: Um trabalhador da contradição. In B. Charlot, C. Luckesi, J. C. Libâneo, J. J.Sonnevile, R. S. Rabelo, E. Maheu et al. (Orgs.) Ser professor na contemporaneidade: Desafios, ludicidade e protagonismo (pp. 15-36). Curitiba, PR: CRV.

Delari, A., Jr. (2009). Vigotski e a prática do psicólogo: Em percurso da psicologia geral à aplicada. Umuarama, PR: Grupo de Estudos em Teoria Histórico-Cultural. Recuperado de: https://pt.scribd.com/document/357294205/ Achille-Delari-VIGOTSKI-E-A-PRATICA-DO-PSICOLOGO-pdf

Dugnani, L. A. C., \& Souza, V. L. T. (2011). Os sentidos do trabalho para o orientador pedagógico: Contribuições da psicologia escolar. Psicologia da Educação, 33(2), 29-47.

Dugnani, L. A. C., \& Souza,V. L. T. (2016). Psicologia e gestores escolares: Mediações estéticas e semióticas promovendo ações coletivas. Estudos de Psicologia (Campinas), 33(2), 247-259. https://doi.org/10.1590/1982-02752016000200007

Fernandes, L. V. (2015). O processo grupal como resistência ao sofrimento e ao adoecimento docente: Um estudo à luz da perspectiva histórico-dialética (Tese de doutorado). Universidade de São Paulo, São Paulo, SP, Brasil. Recuperado de: http://www.teses.usp.br/teses/disponiveis/47/47131/tde-04012016-094754/pt-br.php

Guzzo, R. S. L., Mezzalira, A. S. C., Moreira, A. P. G., Tizzei, R. P., \& Silva, W. M. F., Neto. (2010) Psicologia e educação no Brasil: Uma visão da história e possibilidades nesta relação. Psicologia: Teoria e Pesquisa, 26(esp), 125-136. https://doi.org/10.1590/S0102-37722010000500012

Han, B. C. (2015). Sociedade do cansaço (E. P. Giachini, Trad.). Rio de Janeiro, RJ: Vozes.

Ianni, O. (2004). Variações sobre arte e ciência. Tempo Social-USP, 16(1), 7-23. https://doi.org/10.1590/S010320702004000100001

Lane, S. T. M. (1989). O processo grupal. In A. A. Andrey, A. Naffah Neto, A. C. Ciampa, I. Carone, J. C. Libâneo, J. R. T. Reis et al. (Orgs), Psicologia social: O homem em movimento (8a ed., pp. 78-98). São Paulo, SP: Brasiliense.

Libâneo, J. C. (2012). O dualismo perverso da escola pública brasileira: Escola do conhecimento para os ricos, escola do acolhimento social para os pobres. Educação e Pesquisa, 38(1), 13-28. https://doi.org/10.1590/S1517-97022011005000001

Marx, K., \& Engels, F. (1989). A ideologia alemã. (L. C. Costa, Trad.). São Paulo, SP: Martins Fontes.

Moysés, M. A. A., \& Collares, C. A. L. (2013). Controle e teste: Medicalização da infância. Desidades, 1(1), 11-21.

Patto, M. H. S. (1984). Psicologia e ideologia: Uma introdução crítica à psicologia escolar. São Paulo, SP: T. A. Queiroz.

Patto, M. H. S. (1990). A produção do fracasso escolar. São Paulo, SP: Casa do Psicólogo.

Patto, M. H. S. (1997) Introdução à psicologia escolar. São Paulo, SP: Casa do Psicólogo.

Petroni, A. P., \& Souza, V. L. T. (2014). Psicólogo escolar e equipe gestora: Tensões e contradições de uma parceria. Psicologia: Ciência e Profissão, 34(2), 444-459. https://doi.org/10.1590/1982-3703000372013

Petrovsky, A. V. (1984). Personalidad, actividad y colectividad (A. Kessler, Trad.). Buenos Aires: Cartago.

Roth, M. W., \& Jornet, A. (2016). Perezhivanie: A monist concept for a monist theory. Mind, Culture and Activity, 23(1), 353-355. https://doi.org/10.1080/10749039.2016.1186197

Sawaia, B. B. (1995). Psicologia social: Aspectos epistemológicos e éticos. In S. T. M. Lane, \& B. B. Sawaia (Orgs.), Novas veredas da psicologia social (pp.45-53). São Paulo, SP: Brasiliense.

Sawaia, B. B. (2009). Psicologia e desigualdade social: Uma reflexão sobre liberdade e transformação social. Psicologia \& Sociedade, 21(3), 364-372. https://doi.org/10.1590/S0102-71822009000300010

Sawaia, B. B. (2010). O sofrimento ético-político como categoria de analise da dialética exclusão/inclusão. In B. B. Sawaia (Org.), As artimanhas da exclusão: Análise psicossocial e ética da desigualdade social (10a ed., pp. 99-119). Petrópolis, RJ: Vozes. 
Souza, M. P. R. (2009). Psicologia escolar e educacional em busca de novas perspectivas. Psicologia Escolar e Educacional, 13(1), 179-182. https://doi.org/10.1590/S1413-85572009000100021

Souza, M. P. R. (2010). Psicologia escolar e políticas públicas em educação: Desafios contemporâneos. Em aberto, 23(83), 129-149.

Souza, V. L. T. (2016a). Contribuições da psicologia à compreensão do desenvolvimento e da aprendizagem. In V. L. T. Souza, A. P. Petroni, \& P. C. Andrada (Orgs.), A psicologia da arte e a promoção do desenvolvimento e da aprendizagem: Intervenções em contextos educativos diversos (pp. 11-28). São Paulo, SP: Loyola.

Souza, V. L. T. (2016b). Arte, imaginação e desenvolvimento humano: Aportes à atuação do psicólogo na escola. In M. V. M. Dazzani, \&V. L. T. Souza (Orgs.), Psicologia escolar crítica: Teoria e prática nos contextos educacionais (pp. 73-93). Campinas, SP: Alínea.

Souza, V. L. T., \& Andrada, P. C. (2013). Contribuições de Vigotski para a compreensão do psiquismo. Estudos de Psicologia, 30(3), 355-365. https:// doi.org/10.1590/S0103-166X2013000300005.

Souza, V. L. T., \& Luz, A. F. (2017) As interações em sala de aula nos terceiros anos do ensino fundamental. Interação em Psicologia, 21(2), 137-146. https://doi.org/10.5380/psi.v21i2.35799

Souza, V. L. T., Petroni, A. P., \& Dugnani, L. A. C. (2011). A arte como mediação nas pesquisas e intervenção em psicologia escolar. In R. S. L. Guzzo, \& C. M. Marinho-Araújo, Psicologia escolar: Identificando e superando barreiras (pp. 261-285). Campinas, SP: Alínea.

Souza, V. L. T., Petroni, A. P., \& Andrada, P. C. (2013a). A Afetividade como traço da constituição identitária docente: O olhar da psicologia. Psicologia \& Sociedade, 25(3), 527-537. https:// doi.org/ 10.1590/S0102-71822013000300007

Souza, V. L. T., Petroni, A. P., Dugnani, L. A. C., Andrada, P. C., \& Barbosa. E. T. (2013b). Psicólogo escolar e intervenções na escola: Partilhando experiências. In M. H. Bernardo, R. S. L. Guzzo, \& V. L. T. Souza (Orgs.), Psicologia social: Perspectivas críticas de atuação e pesquisa (pp. 117-149). Campinas, SP: Alínea.

Souza, V. L. T., Dugnani, L. A. C., Petroni, A. P., \& Andrada, P. C. (2015). A síntese como registro reflexivo no trabalho do psicólogo escolar com gestores. Psicologia da Educação, (41), 83-94. https://doi.org/10.5935/2175-3520.20150016

Souza, V. L. T., Dugnani, L. A. C., \& Reis, E. C. G. (2018). Psicologia da arte: Fundamentos e práticas para uma ação transformadora. Estudos de Psicologia (Campinas), 35(4), 375-388. https://doi.org/10.1590/1982-02752018000400005

Spinoza, B. (2009). Ética (T. Tadeu, Trad.). Rio de Janeiro, RJ: Autêntica. (Obra original publicada em 1677).

Vinha, M. P., \& Welcman, M. (2010). Quarta aula: A questão do meio na pedologia. Psicologia USP, 21(4), 681-701. https://doi.org/10.1590/S0103-65642010000400003

Vygotsky, L. S. (2001). Psicologia da arte (2a ed.). São Paulo, SP: Martins Fontes. (Obra original publicada em 1925).

Vygotsky, L. S. (2004a). O significado histórico da crise da psicologia: Uma investigação metodológica. In L. S. Vygotsky, Teoria e método em psicologia (3a ed., pp. 203-417). São Paulo, SP: Martins Fontes. (Obra original publicada em 1927).

Vygotsky, L. S. (2004b) O método instrumental em psicologia. In L. S. Vygotsky, Teoria e método em psicologia (3a ed., pp. 93-189). São Paulo, SP: Martins Fontes. (Obra original publicada em 1930).

Vygotsky, L. S. (2007). A formação social da mente: O desenvolvimento dos processos psicológicos superiores (7a ed.). São Paulo, SP: Martins Fontes. (Obra original publicada em 1931).

Vygotsky, L. S. (2010). Pensamento e palavra. In L. S. Vygotsky, A construção do pensamento e da linguagem. São Paulo, SP: Martins Fontes. (Obra original publicada em 1934).

Paula Costa de Andrada

Doutora e Mestre em Psicologia como Profissão e Ciência pela Pontifícia Universidade Católica de Campinas (PUC-Campinas), Campinas - SP. Brasil. Supervisora de estágio e docente de Psicologia Escolar e Psicologia Social no Centro Universitário UNIFAAT, Atibaia - SP. Brasil.

E-mail: p.andrada@uol.com.br

http://orcid.org/0000-0001-5437-4102 


\section{Lilian Aparecida Cruz Dugnani}

Doutora e Mestre em Psicologia como Profissão e Ciência pela Pontifícia Universidade Católica de Campinas (PUC-Campinas), Campinas - SP. Brasil. Professora colaboradora da PUC-Campinas.

E-mail: lac.dugnani@gmail.com

D http://orcid.org/0000-0002-6888-6130

\section{Ana Paula Petroni}

Doutora e Mestre em Psicologia como Profissão e Ciência pela Pontifícia Universidade Católica de Campinas (PUC-Campinas), Campinas - SP. Brasil. Professora do curso de graduação em Psicologia da PUC-Campinas.

E-mail: anappetroni@gmail.com

D http://orcid.org/0000-0002-2584-693X

Vera Lucia Trevisan de Souza

Doutora e Mestre em Psicologia da Educação pela Pontifícia Universidade Católica (PUC), São Paulo - SP. Brasil. Docente e pesquisadora da PUC, Campinas - SP. Brasil.

E-mail: vera.trevisan@uol.com.br

(D) http://orcid.org/0000-0003-2062-0680

Endereço para envio de correspondência:

Pontifícia Universidade Católica de Campinas, Centro de Ciências da Vida,

Programa de Pós-Graduação em Psicologia.

Av. Jonh Boyd Dunlop, s/n, Prédio Administrativo, Jd. Ipaussurama,

CEP: 13059-900. Campinas - SP. Brasil.

Recebido 01/11/2017

Reformulado 17/12/2018

Aceito 09/01/2019

Received 11/01/2017

Reformulated $12 / 17 / 2018$

Approved 01/09/2019

Recibido 01/11/2017

Reformulado 17/12/2018

Aceptado 09/01/2019

Como citar: Andrada, P. C.; Dugnani, L. A. C.; Petroni, A. P. e Souza, V. L. T. (2019). Atuação de Psicólogas (os) na Escola: Enfrentando Desafios na Proposição de Práticas Críticas. Psicologia: Ciência e Profissão, 39, 1-16.

https://doi.org/10.1590/1982-3703003187342

How to cite: Andrada, P. C.; Dugnani, L. A. C.; Petroni, A. P. e Souza, V. L. T. (2019). Psychologists' Performance at School: Facing Challenges in Proposing Critical Practices. Psicologia: Ciência e Profissão, 39, 1-16.

https://doi.org/10.1590/1982-3703003187342

Cómo citar: Andrada, P. C.; Dugnani, L. A. C.; Petroni, A. P. e Souza, V. L. T. (2019). Actuación de Psicólogas(os) en la Escuela: Enfrentando Desafíos para Proponer Prácticas Críticas. Psicologia: Ciência e Profissão, 39, 1-16.

https://doi.org/10.1590/1982-3703003187342 